\title{
Use of Weather and Climate Information in Decisions on Conservation of Water Resources in Kilombero River Catchment, Tanzania
}

\author{
Emanuel L. Moirana $^{1 *} \quad$ J.J. Kashaigili ${ }^{2}$ \\ 1.Department of Wildlife Management, P.O. Box 3017, Sokoine University of Agriculture, Chuo Kikuu, \\ Morogoro, Tanzania. \\ 2.Department of Forest Resources Assessment and Management, P.O. Box 3013, Sokoine University of \\ Agriculture, Chuo Kikuu, Morogoro, Tanzania.
}

The authors thankfully acknowledge the financial support from Uncertainty Reduction in Models for Understanding Development Applications (UMFULA) Project under the Future Climate for Africa (FCFA). Special thanks go to Declan Conway (London School of Economics and Political Science) who contributed invaluable inputs to the publication.

\section{Abstract}

This study assessed the use of climate information in decisions on the conservation of water resources and determined influencing factors in Kilombero River Catchment in Tanzania. A cross-sectional research design was employed. Purposive sampling was used to select Kilombero, Ulanga and Malinyi districts and Lumemo, Nakafulu and Biro villages while simple random sampling was used to select respondents. A total of 120 household respondents were interviewed in the three villages. In addition, 7 Key Informants' Interviews (KIIs) involving officers from Kilombero Game Controlled Area (KGCA) and Rufiji Basin Water Board (RBWB) and 3 Focus Group Discussions (FGDs) with the villagers were conducted. Quantitative data were analyzed using Statistical Package for Social Science (SPSS) and STATA computer programs while qualitative information was analyzed using content analysis. Results show nearly half of respondents of weather and climate information in decisions to conserve water resources. Although ten decisions were identified in the area, weather and climate information was highly used in deciding conservation measures $\left(X^{2}=5.992, p<0.05\right)$, construction of small pans or bore holes for water storage $\left(\mathrm{X}^{2}=6.580,<0.05\right)$ and reducing the number of livestock $\left(\mathrm{X}^{2}=5.889, \mathrm{p}<0.05\right)$. Four variables which had significant and positive correlation with conservation of water resources were identified. Foremost among them is extension visits $(\beta=0.079 ; p<0.01)$ which implied access and frequency of extension visits influence use of weather and climate information in making decisions. It is concluded that communities in the area use weather and climate information in decisions which conserve water resources. Policy makers are advised to emphasize factors which had positive significant correlation with conservation of water resources.

Keywords: Climate Information Use, Water Conservation Decisions.

DOI: $10.7176 / \mathrm{JEES} / 10-4-06$

Publication date: April $30^{\text {th }} 2020$

\section{Introduction}

Information on weather (hours to months) and climate (months to decades) are useful tools for building adaptive capacities of communities and governments to climate change (Ambani \& Abalabe 2017). It does this by reducing the vulnerability of societies and people to the effects of increased variability and changes through; reducing shifts in hydro-meteorological trends, protect and restore ecosystems that provide critical land and water resources and closing the gap between water supply and demand (Bergkamp et al. 2003). Yet, little is known regarding the uses of weather and climate information in decisions on the conservation of water resources in Tanzania, especially in the Kilombero River catchment.

The Kilombero River catchment is one of the largest seasonal freshwater lowland floodplains in East Africa and it joins the Great Ruaha, Rufiji and Luwegu Rivers in the Rufiji River basin (Wilson et al. 2017). The area is of global, national and local significance ranging from the provision of water for a number of functions such as domestic use, agriculture and industrial activities to supporting the ecology of seasonally migrating animals in Selous-Mikumi ecosystem (Lyon et al. 2015; Wilson et al. 2017). The aim of this study was to investigate climate information use for water resources conservation. The specific objectives are as follows; 1 , to assess the use of climate information on decisions to conserve water resources, and 2, to determine factors that influence the use of weather and climate information in decisions on conservation of water resources.

\section{Materials and Methods}

\subsection{Study Area Description}

This study was conducted in Lumemo, Nakafulu and Biro villages of Kilombero, Ulanga and Malinyi districts in Kilombero River catchment within the Rufiji River Basin. The river catchment is located between Longitudes 
$34^{\circ} 33^{\prime} \mathrm{E}$ and $37^{\circ} 20^{\prime} \mathrm{E}$ and Latitudes $7^{\circ} 39^{\prime} \mathrm{S}$ and $10^{\circ} 01^{\prime} \mathrm{S}$ (Figure 1). The area shares borders with the Udzungwa Mountains to the north and west and with Mahenge highlands to the east and is surrounded by steep slopes rising up to 2,576 meters above sea level (m.a.s.l.) in the north-western side while the land rises more gradually along the southeastern side reaching a maximum height of 1,516 m.a.s.1. (Minas 2014).

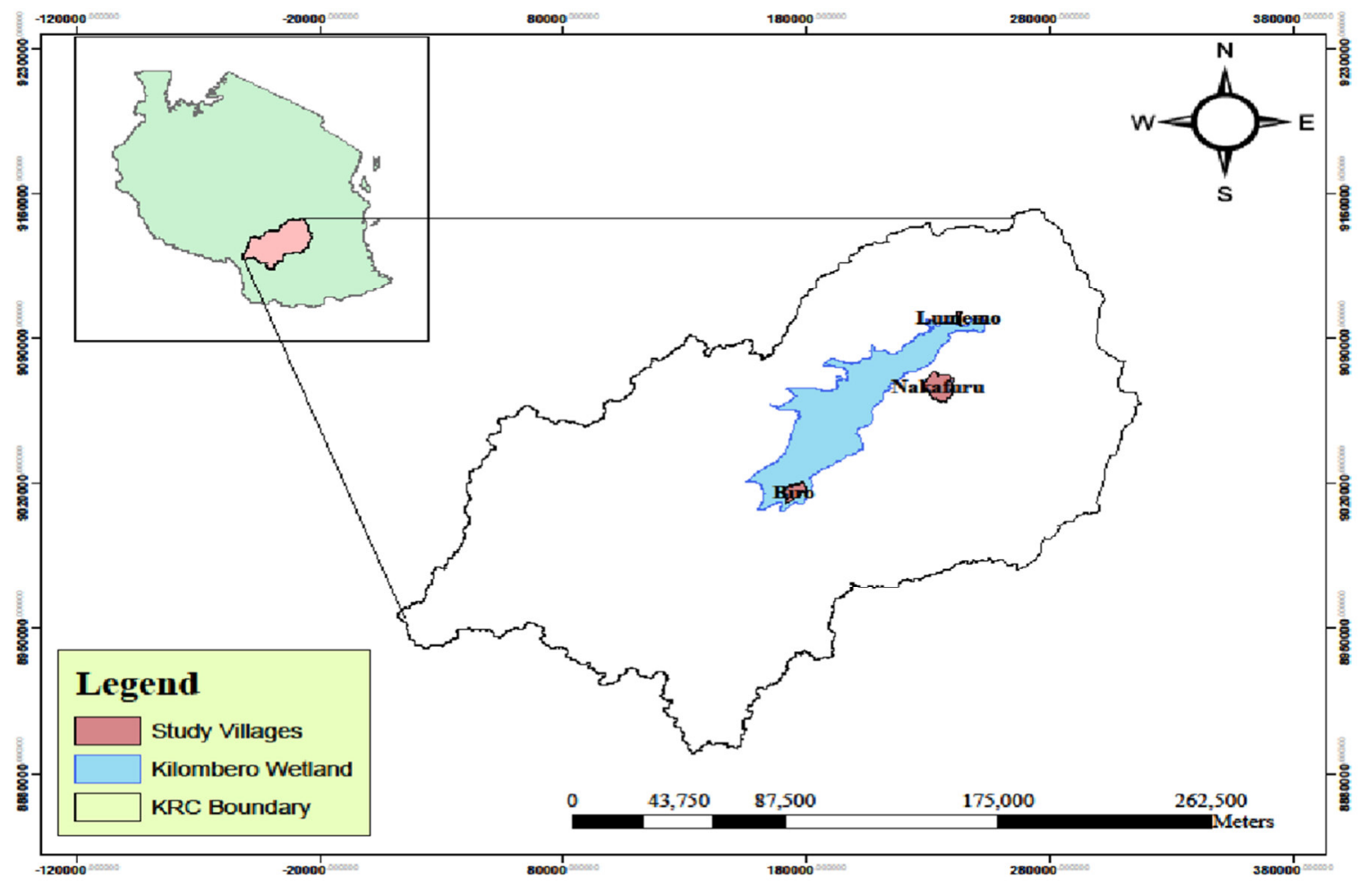

Figure 1: Location of Kilombero River catchment in Tanzania and study villages

\subsection{Research Design, Sampling Procedure and Sample Size}

A cross-sectional research design was employed in this study (Kothari 2004). Data were collected once at a single point in time involving farmers who were the majority, with far fewer fisherman and pastoralists in the area. Purposive and simple random samplings were used in selecting study districts, villages and respondents. Three districts (Kilombero, Malinyi and Ulanga) were selected purposively because they occupy a larger portion of the river catchment while three villages (Lumemo, Nakafulu and Biro) were selected because they had enormous water resources and accessibility.

Respondents were randomly selected using a sampling frame formed by a village resister. Purposive sampling was also used in selecting participants for key informant interviews (KIIs) from Kilombero Game Controlled Area (KGCA) and Rufiji Basin Water Board (RBWB) in Kilombero and for focus group discussions (FGDs) from the three villages. A total of 120 respondents, forty respondents from each village were interviewed and 7 KIIs and 3 FGDs with 9-12 participants conducted using a checklist.

\subsection{Data Collection}

The study employed multiple data collection tools, including direct observations, household questionnaire and checklist for KIIs and FGDs.

\subsection{Data Analysis}

Quantitative data were analyzed using Statistical Package for Social Science (SPSS) version 20 and STATA computer programs. The SPSS yielded descriptive statistics such as frequency and percentage as well as crosstabulations and Chi-square analyses. The use of weather and climate information was determined by the adoption quotient (Farid et al., 2015). The adoption quotient for an individual respondent was calculated based on the use scores gained by respondents for the use of weather and climate information. Ten decisions on water resources conservation were recorded in the three villages and were all used for calculation of the use quotient.

$$
\text { Adoption quotient }=\frac{\text { Total use score gained by respondents }}{\text { Maximum use scores }} \times 100
$$

On the basis of the adoption quotient, farmers were classified into three categories for Chi-square analysis, such as low use $=<($ Mean $-1 \mathrm{SD})$, medium use $=($ Mean $\pm 1 \mathrm{SD})$ and high use $=>($ Mean $+1 \mathrm{SD})$. For two-limit Tobit 
regression analysis in STATA, use/adoption quotient formed a dependent variable and was used as a continuous variable while the independent variables were; climate information attributes (local and scientific forecasts), sources of climate information (radio, television, extension visits, neighbours or relatives, traditional methods and village meetings), wealth status, economic activity, position in community, size of land owned, age, gender and education level (Table 1). The model was used in this study because it can measure both probability and extent of use of climate information in each decision while minimizing inadequacies such as heteroscedastic disturbance term $(\mu \mathrm{i})$ produced inherently by other linear probability models leading to biases of standard deviations of estimates (Sileshi et al., 2012).

\section{The Tobit model used was}

$$
\begin{aligned}
& Y^{*}=\beta x_{i}+\epsilon_{i} \in \sim N\left[0, \delta^{2}\right] Y^{*}=\beta x_{i}+\epsilon_{i}, \epsilon \sim N\left[0, \delta^{2}\right] \\
& Y_{i}=\beta 0+\beta_{1} X_{1 \ldots \ldots} \beta_{n} X_{n} i=1 \ldots n Y_{i}=\beta 0+\beta_{1} X_{1 \ldots \ldots} \beta_{n} X_{n \ldots} i=1 \ldots n
\end{aligned}
$$

Denoting $\mathrm{Y}_{\mathrm{i}}$ as the observed dependent (censored) variable;

$$
\left\{\begin{array} { c } 
{ 0 \text { if } \mathrm { Y } _ { \mathrm { i } } ^ { * } \leq 0 } \\
{ \mathrm { Y } _ { \mathrm { i } } = \mathrm { Y } _ { \mathrm { i } } ^ { * } = \mathrm { X } \beta + \mu \text { if } 0 < \mathrm { Y } ^ { * } < 1 } \\
{ 1 \text { if } \mathrm { Y } _ { \mathrm { i } } ^ { * } \geq 1 }
\end{array} \left\{\begin{array}{c}
0 \text { if } \mathrm{Y}_{\mathrm{i}}^{*} \leq 0 \\
\mathrm{Y}_{\mathrm{i}}=\mathrm{Y}_{\mathrm{i}}^{*}=\mathrm{X} \beta+\mu \mathrm{if} 0<\mathrm{Y}^{*}<1 \\
1 \text { if } \mathrm{Y}_{\mathrm{i}}^{*} \geq 1
\end{array}\right.\right.
$$

Where;

$\mathrm{Yi}=$ observed dependent variable,

$\mathrm{Yi}^{*}=$ latent variable (unobserved for values less than 0 and greater than 1 ),

$\mathrm{Xi}=$ vector of independent variables (factors affecting climate information use),

$\beta 1=$ vector of unknown parameters, and

$\mu \mathrm{i}=$ normally distributed residuals.

Although the regression parameters do not directly correspond to the changes in the expected level of usage, their signs indicate the direction of change in the probability of use and marginal intensity of use as the respective explanatory variable change (Sileshi et al. 2012). Qualitative data were analyzed using content analysis where pieces of information were organized into different themes and compared based on the study objectives.

Table 1: Description of independent variables included in the two-limit Tobit model

\begin{tabular}{|c|l|c|}
\hline Variable & Variable description & Expected sign \\
\hline X1 & Local climate attributes (1 if available, 0 if Otherwise) & + \\
\hline X2 & Scientific climate attributes (1 if available, 0 if Otherwise) & + \\
\hline X3 & Access to the radio (1 if yes, 0 if Otherwise) & + \\
\hline X4 & Access to television (1 if yes, 0 if Otherwise) & + \\
\hline X6 & Extension visits (number and frequency) (1 if yes, 0 if Otherwise) & $+/-$ \\
\hline X7 & Traditional methods (number) (1 if available/used, 0 if Otherwise) & + \\
\hline X8 & Household income (1 if low income, 0 if Otherwise) & $+/-$ \\
\hline X9 & Main economic activity of respondent (1 if farmer, 0 if Otherwise) & + \\
\hline X10 & Position in community (1 if Ordinary citizen, 0 if Otherwise) & $+/-$ \\
\hline X11 & Size of land owned or used in ha (1 if "3-5”, 0 if Otherwise) & $+/-$ \\
\hline X12 & Household age (category) (1 if “40-59”, 0 if Otherwise) & + \\
\hline X13 & Gender of household head (1 if Male, 0 if Female) & $+/-$ \\
\hline X14 & Education level in category (1 if primary, 0 if Otherwise) \\
\hline
\end{tabular}

\section{Results}

\subsection{Socio-demographic Characteristics of Respondents}

The results show that the majority $53.3 \%$ of the respondents were aged between 40 and 59 years, $65.8 \%$ were males and $91.7 \%$ were married (Table 2). This indicates most of households in the area are male-headed. Farmers $(91 \%)$ dominated the study villages followed by far with fisherman $(5.0 \%)$ and pastoralists $4.2 \%)$ (Table 2). This indicates weather and climate information attributes related to rainfall are the most prominent in the area. As for land ownership, 19.1\% owned less than 3 hectares (ha) $26.7 \%$ owned 3 to 5 ha and more than half $54.2 \%$ owned more than 5 ha (Table 2). The large size of land owned by the majority is allocated to them by the village government or inherited from parents (Harrison 2006). Results also indicate that most $77.5 \%$ of the respondents belonged to the low-income category $85.0 \%$ had completed primary school education (Table 2). This has serious implication on climate change awareness issued because education plays an important role in raising awareness. 
Table 2: The respondents' socio-demographic characteristics $(n=120)$

\begin{tabular}{|c|c|c|c|c|c|}
\hline \multirow[t]{2}{*}{ Characteristics } & \multirow[t]{2}{*}{ Category } & \multicolumn{3}{|c|}{ Name of Village } & \multirow{2}{*}{$\begin{array}{c}\text { Total } \\
\text { (Average) }\end{array}$} \\
\hline & & Lumemo & Nakafuru & Biro & \\
\hline \multirow[t]{3}{*}{ Age of respondent } & $20-39$ & 12.5 & 27.5 & 15.0 & 18.3 \\
\hline & $40-59$ & 42.5 & 50.0 & 67.5 & 53.3 \\
\hline & $>=60$ & 45.0 & 22.5 & 17.5 & 28.3 \\
\hline \multirow[t]{3}{*}{ Land size (ha) } & Less than 3 & 32.5 & 10.0 & 15.0 & 19.2 \\
\hline & $3-5$ & 27.5 & 25.0 & 27.5 & 26.7 \\
\hline & More than 6 & 40.0 & 65.0 & 57.5 & 54.2 \\
\hline \multirow[t]{2}{*}{ Sex } & Male & 77.5 & 42.5 & 77.5 & 65.8 \\
\hline & Female & 22.5 & 57.5 & 22.5 & 34.2 \\
\hline \multirow{2}{*}{ Marital status } & Married & 97.5 & 82.5 & 95.0 & 91.7 \\
\hline & Single & 2.5 & 17.5 & 5.0 & 8.3 \\
\hline \multirow[t]{4}{*}{ Education in level } & Illiterate & 10.0 & 2.5 & 5.0 & 5.8 \\
\hline & Primary & 67.5 & 95.0 & 92.5 & 85.0 \\
\hline & Secondary \& high school & 15.0 & 2.5 & 2.5 & 6.7 \\
\hline & Graduate and above & 7.5 & 0.0 & 0.0 & 2.5 \\
\hline \multirow[t]{3}{*}{ Household income } & Low & 62.5 & 82.5 & 87.5 & 77.5 \\
\hline & Medium & 37.5 & 10.0 & 12.5 & 20.0 \\
\hline & High & 0.0 & 7.5 & 0.0 & 2.5 \\
\hline \multirow[t]{3}{*}{ Economic activity } & Farmer & 82.5 & 95.0 & 95.0 & 90.8 \\
\hline & Pastoralist & 7.5 & 2.5 & 2.5 & 4.2 \\
\hline & Fisherman & 10.0 & 2.5 & 2.5 & 5.0 \\
\hline
\end{tabular}

\subsection{Status on Use of Weather and Climate Information}

Results show respondents in the study area made ten decisions which are to farm or other undertakings, change farming practices, protecting water resources, conservation actions, regulate water use, improve water irrigation systems, construction of small pans/ bore holes, move to other areas, reduce number of livestock and look for offfarm jobs (Table 3). Among all decisions, 'farming or other undertakings' use is the highest and 'improve water irrigation systems' is the lowest in nearly all villages (Table 3). Significant variations in use are observed in three water conservation decisions in the three villages; conservation actions $\left(X^{2}=5.992, p<0.05\right)$, construct small pans/bore holes for water storage $\left(X^{2}=6.580,<0.05\right)$ and reduce the number of livestock $\left(X^{2}=5.889, p<0.05\right)$ (Table 3). The main reason is the variations in the socio-economic characteristics of the respondents of the three villages (Table 3). Apart from farming or engage in other undertakings (79.2\%), decisions on changing farming practices $(74.2 \%)$, conservation activities $(71.7 \%)$ and protection of water resources $(70.0 \%)$ were used by more than half of all the respondents (Table 3).

Table 3: Water resources conservation decisions implemented in Kilombero River Catchment $(\mathbf{n}=120)$

\begin{tabular}{|c|l|c|c|c|c|c|}
\hline S/n & Water conservation decisions & Lumemo & Nakafulu & Biro & $\begin{array}{c}\text { Chi- } \\
\text { square }\end{array}$ & $\begin{array}{c}\text { P- } \\
\text { value }\end{array}$ \\
\hline 1 & Conservation actions, e.g. trees planting & 77.5 & 80 & 57.5 & 5.992 & 0.05 \\
\hline 2 & $\begin{array}{l}\text { Protecting water resources, e.g. restrict human } \\
\text { activities }\end{array}$ & 75 & 72.5 & 62.5 & 1.667 & 0.44 \\
\hline 3 & $\begin{array}{l}\text { Change in farming practices, e.g. drought } \\
\text { resistant crops }\end{array}$ & 72.5 & 77.5 & 72.5 & 0.348 & 0.84 \\
\hline 4 & $\begin{array}{l}\text { Regulate water use, e.g. reduce the irrigation } \\
\text { rate }\end{array}$ & 17.5 & 10 & 12.5 & 1.010 & 0.60 \\
\hline 5 & $\begin{array}{l}\text { Improve water irrigation systems, e.g. clearing } \\
\text { of canals }\end{array}$ & 17.5 & 12.5 & 12.5 & 0.548 & 0.76 \\
\hline 6 & $\begin{array}{l}\text { Construct small pans or bore holes to store } \\
\text { water }\end{array}$ & 30 & 12.5 & 10.0 & 6.580 & 0.04 \\
\hline 7 & Farming or other undertakings & 72.5 & 82.5 & 82.5 & 1.617 & 0.45 \\
\hline 8 & Move to other areas (for many reasons). & 42.5 & 32.5 & 20 & 4.698 & 0.10 \\
\hline 9 & Reduce the number of livestock & 37.5 & 35 & 15 & 5.889 & 0.05 \\
\hline 10 & $\begin{array}{l}\text { Off-farm jobs e.g. employment on a temporary } \\
\text { basis }\end{array}$ & 37.5 & 15 & 22.5 & 6.600 & 0.06 \\
\hline
\end{tabular}

The least frequently adopted decisions on water resources conservation was the construction of small pans or bore holes for water storage $(17.5 \%)$, improvement of water irrigation systems $(14.2 \%)$ and regulate water use 
(13.3\%) (Table 3). These three water conservation decisions were used by less than $20 \%$ of all respondents because the majority of respondents had low income and they could not afford such intervention.

\subsection{Extent of Use of Weather and Climate Information in Decisions to Conserve Water Resources}

Results have shown the mean use score of weather and climate information in decisions on conservation of water resources is $44 \%$ with a standard deviation of $23.5 \%$ and adoption quotient is 40 for more than 40 respondents interviewed in the area (Figure. 2).

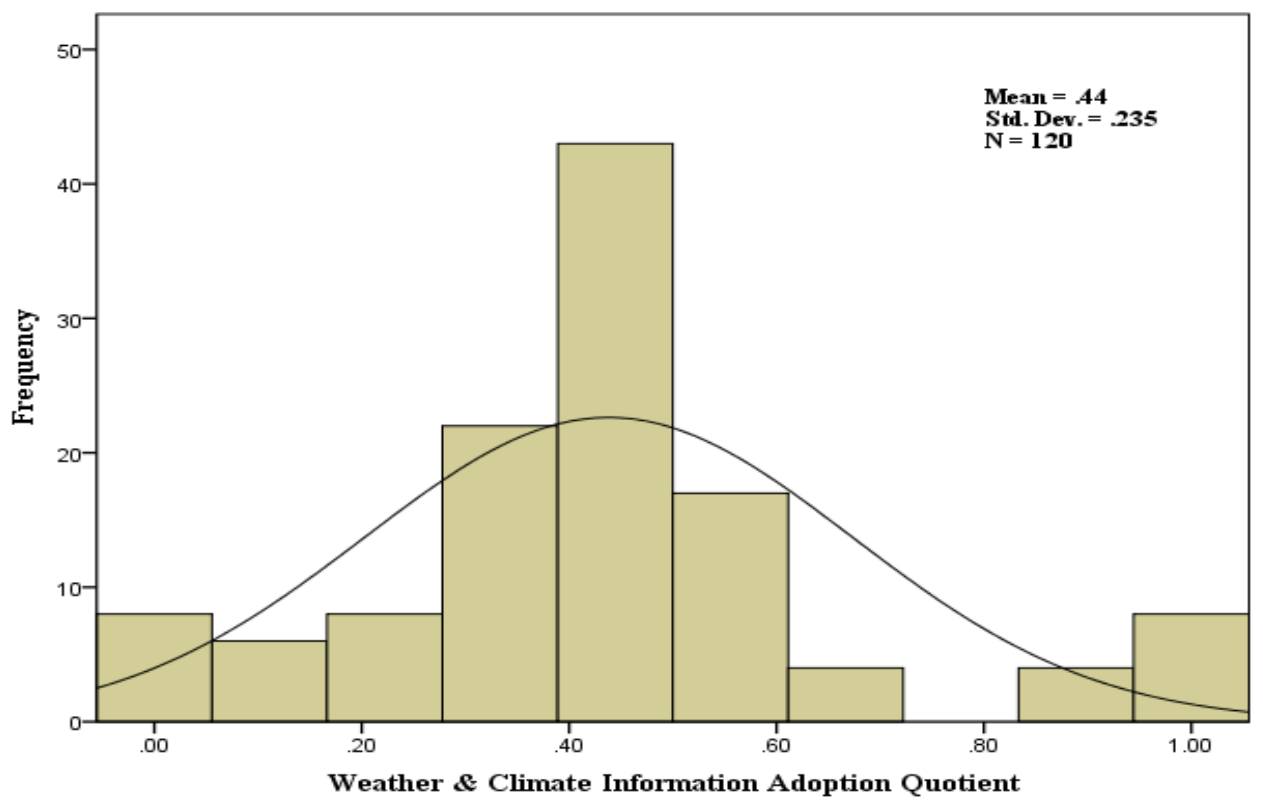

Figure 2. The extent of use of weather and climate information by respondents

There was overall medium use of weather and climate information $34.7 \%, 33.7 \%$ and $31.6 \%$ of respondents from Lumemo, Nakafulu and Biro villages, although Lumemo village had a larger portion of respondents $50 \%$ in the high use category (Table 4). The Chi-square test (5.147, $\mathrm{P}>0.05)$ indicates there were associations on weather and climate information use among the three villages; Lumemo, Nakafulu and Biro.

Table 4: Distribution of respondents based on three categories of use

\begin{tabular}{|l|c|c|c|c|c|}
\hline \multirow{2}{*}{ Use category } & \multicolumn{3}{|c|}{ Study villages } & \multirow{2}{*}{ Total } & \multirow{2}{*}{ Chi-square } \\
\cline { 2 - 4 } & Lumemo & Nakafuru & Biro & & \multirow{2}{*}{5.147} \\
\hline Low use & $2(13.3)$ & $5(33.3)$ & $8(53.3)$ & $15(12.5)$ & \\
\hline Medium use & $33(34.7)$ & $32(33.7)$ & $30(31.6)$ & $95(79)$ & \\
\hline High use & $5(50)$ & $3(30)$ & $2(20)$ & $10(8.3)$ & \\
\hline
\end{tabular}

Source: Field Survey, 2017. Note: Figures within parentheses indicate percent use

\subsection{Factors affecting Decisions to Use Weather and Climate Information in Decisions to Conserve Water Resources}

The likelihood ratio $\chi^{2}$ of $45.98(14)$ with a $(p<0.05)$ in two limit Tobit regression model indicates that the model as a whole fits significantly while the coefficient of determination $\left(\mathrm{R}^{2}\right)$ of 0.75 indicating $75 \%$ of the total variation in use of weather and climate information is attributed to variables fitted in the model. Fourteen explanatory variables were fitted in the model (Table 5). Six variables were found to significantly influence the probability and extent of use of weather and climate information (Table 5). Four variables, namely scientific attributes $(\beta=0.182 ; \mathrm{p}<0.01)$, extension visits $(\beta=0.079 ; \mathrm{p}<0.01)$, traditional methods $(\beta=0.114 ; \mathrm{p}<0.05)$ and household income $(\beta=0.072 ; p<0.05)$ were positively correlated while economic activity $(\beta-0.152 ; p<0.05)$ and education level $(\beta=-0.111 ; \mathrm{p}<0.05)$ negatively correlated (Table 5). 
Table 5: Results of Tobit model estimates of intensity and factors influencing decisions to use weather and climate information

\begin{tabular}{|c|c|c|c|c|c|c|}
\hline Variable & $\boldsymbol{\beta}$ & SE & t-value & Sig. & Probability & $\begin{array}{r}\text { Unconditional } \\
\text { Expected } \\
\text { Value } \\
\end{array}$ \\
\hline Local attributes (X1) & -0.040 & 0.056 & -0.70 & 0.486 & -0.008 & -0.038 \\
\hline Scientific attributes (X2) & 0.182 & 0.056 & 3.24 & $0.002 *$ & 0.071 & 0.173 \\
\hline Access to radio (X3) & 0.125 & 0.065 & 1.92 & 0.058 & 0.042 & 0.120 \\
\hline Access to television $(\mathrm{X} 4)$ & -0.064 & 0.054 & -1.18 & 0.239 & -0.014 & -0.062 \\
\hline Extension visits(X5) & 0.079 & 0.022 & 3.51 & $0.001 * *$ & 0.017 & 0.076 \\
\hline Traditional methods(X6) & 0.114 & 0.057 & 2.01 & $0.047 *$ & 0.035 & 0.118 \\
\hline Village meetings $(X 7)$ & -0.106 & 0.065 & -1.63 & 0.106 & -0.036 & -0.102 \\
\hline Wealth status (X8) & 0.072 & 0.033 & 2.16 & $0.033 *$ & 0.016 & 0.070 \\
\hline Economic activity(X9) & -0.152 & 0.069 & -2.19 & $0.031 *$ & -0.033 & -0.147 \\
\hline Position in community (X10) & 0.013 & 0.081 & 0.16 & 0.87 & 0.003 & 0.012 \\
\hline Size of land owned(X11) & -0.030 & 0.020 & -1.52 & 0.13 & -0.007 & -0.029 \\
\hline Age (X12) & 0.035 & 0.032 & 1.05 & 0.296 & 0.008 & 0.033 \\
\hline Gender (X13) & 0.009 & 0.047 & 0.18 & 0.855 & 0.002 & 0.008 \\
\hline Education level (X14) & -0.111 & 0.049 & -2.26 & $0.026^{*}$ & -0.025 & -0.108 \\
\hline Constant & 0.315 & 0.157 & 2.01 & 0.047 & -0.007 & -0.038 \\
\hline Number of observations & 120 & & & & & \\
\hline $\operatorname{LR~chi}^{2}(14)$ & $45.98(14)$ & & & & & \\
\hline Probability $>$ chi 2 & 0 & & & & & \\
\hline Pseudo $\mathrm{R}^{2}$ & 0.75 & & & & & \\
\hline Log-likelihood & -7.52939 & & & & & \\
\hline Censoring observation & & \multicolumn{5}{|c|}{7 left-censored, 105 uncensored, 8 right-censored } \\
\hline
\end{tabular}

Dependent variable: Use/Adoption quotient.

$\beta=$ Coefficient; $S E=$ Standard error.

Note:* and $* *$ indicates statistical significance at 0.05 and 0.001 significance levels.

\section{Discussion}

\subsection{Socio-demographic Characteristics of Respondents}

The age group of 40-59 scored by the majority of respondents is considered to have massive experience on local climate changes and adaptation mechanism. Harrison (2006) noted similar results in a socio-economic baseline survey conducted in 19 villages within the Kilombero River catchment. This concludes that most villages in the river catchment share similar characteristics. FGDs conducted in the three villages revealed that a higher percentage of the ageing population in the area is a result of youth moving to the towns to seek for economic opportunities. Farming activity as scored by majority respondents indicates weather and climate information attributes related to rainfall are the most prominent in the area. Similarly, large size of land owned by the majority is a result of allocations from the village government and inherited from parents (Harrison, 2006).

\subsection{Status on Use of Weather and Climate Information in Kilombero River Catchment}

The study showed weather and climate information is used in the study area to make decisions which conserve water resources. Van Aelst \& Holvoet (2017) supports this observation through a study done in Morogoro rural and Mvomero districts which noted common climate change adaptation strategies by women to encompass; engage in undertakings such as work as a casual labourer on someone else's farmland in return for cash, food or a share in crop yields, engage in income-earning activities outside the household and farm such as brick making, charcoal production, own business and changing farming practices by planting crops that are able to cope with drought conditions such as cassava and millet as observed here too.

There was significant variations in use on conservation actions $\left(X^{2}=5.992, p<0.05\right)$, construction of small pans/boreholes for water storage $\left(X^{2}=6.580,<0.05\right)$ and reduce the number of livestock $\left(X^{2}=5.889, p<0.05\right)$. The main reason for the variations in use is socio-economic characteristics of the respondents of the three villages. During FGDs it was revealed that villagers in the study area are aware and take seriously conservation activities such as planting of trees and protection of water resources because of extension visits and village meetings. Individual respondents in the three villages have been implementing these actions under the influence of village governments who use bye-laws and environmental legislation to compel farmers to ensure water resources are protected. FGDs in Lumemo village highlighted the Environmental Management Act (EMA) of 1997 to be the main act used and they went further to cite 'Section 34' of the law which prohibit human activities near water 
sources to a distance beyond 60 meters as widely used and very useful in protecting water resources.

In Nakafulu village, respondent's awareness of the need to conserve water resources was high as observed by the researcher's in the field through actions taken by pastorals: "Three fishermen were arrested at midnight by pastorals and brought to the village office for further legal action after they were trapped emptying water in one of few remaining water dams/pans in the village to catch catfish easily in November 2017". This implies that communities were aware of appropriate adaptation strategies. KIIs also noted that most water conservation decisions implemented in the area were largely attributed by policies and regulations: "Policies and regulations especially the National Environmental Policy (NEP) of 1997, NAWAPO of 2002, National Wildlife Policy (NWP) of 1997, Environmental Management Act (EMA) No. 20 of 2007, WRMA No. 11 of 2009 and Wildlife Conservation Act (WCA) of 2009 have been central in ensuring water resources such as the Kilombero wetland several rivers are conserved in the Kilombero River catchment" (Field data, KIIs of RBWB and KGCA, 2017).

The construction of small pans/boreholes for water storage (17.5\%), improvement of water irrigation systems $(14.2 \%)$ and regulate water use $(13.3 \%)$ were least made decisions because majority of respondents were of low income and had no irrigated farms. According to Van Aelst \& Holvoet (2017), household income was found to limit adaptations alternatives especially those with higher costs.

\subsection{Extent of Use of Weather and Climate Information in Decisions to Conserve Water Resources}

The adoption in this study refers to use of weather and climate information on decision to conserve water resources. The mean use score of weather and climate information in decisions on conservation of water resources is $44 \%$ with a standard deviation of $23.5 \%$ and majority $(79 \%)$ of respondents in the three villagers were under the medium level of use of the overall adoption quotient. The medium use was evenly distributed $(34.7 \%),(33.7 \%)$ and $(31.6 \%)$ in Lumemo, Nakafulu and Biro villages. The main reason is socio-economic activity which was dominated by farmers. Low use was experienced in Biro while high use was experienced in Lumemo. The probable reason is because Biro village was underdeveloped while Lumemo is was more developed and near urban compared to Nakafulu and Biro villages. Similarly, there were associations on weather and climate information use among the three villages as revealed by Chi-square test $(5.147, \mathrm{P}>0.05)$.

\subsection{Factors affecting Decisions to Use Weather and Climate Information in Decisions to Conserve Water Resources}

The two limit Tobit regression model revealed six variables; scientific attributes, extension visits, traditional methods, household income, economic activity and education level out of 14 fitted explanatory variables significantly influence the probability and extent of use of weather and climate information. The information from scientific sources such as TMA are important in influencing the probability of use in decisions which conserve water resources. This variable was significant and positively correlated $(\beta=0.182 ; p<0.01)$ with the use of weather and climate information. This implies more weather and climate information from scientific sources increases the probability of its use by $7.1 \%$ of farmers in decisions pertaining to farming which contributes towards water resources conservation by $17.3 \%$ of the entire sample. Hansen et al. (2007) noted historic climate records obtained from real-time monitoring reduces uncertainties to farmers thereby increasing their use.

The extension visits had a significant and positive relationship with use of climate information in the area $(\beta=0.079 ; p<0.01)$. This implies access to extension services and frequency of visits determines decisions made by farmers on conservation of water resources and environmental protection in general. The model's results suggest each additional contact increases the probability of use by $1.7 \%$ and intensify of use on water resources conservation decision by $7.6 \%$ of the entire sample. These findings are in line with Idrisa et al. (2012) who noted in Nigeria that farmers with access to extension contact adopt farming technologies by $72 \%$ more than farmers without access to extension contacts. In the study area, extension visits involve educating farmers on environmental conservation, environmental legislation and by-laws formulated by the village government to conserve water resources. Maponya \& Mpandeli (2013) also observed that extension services expose farmers to new information and technical skills which enhances them to make decisions. The use of traditional ways in disseminating climate information emanates from the fact that many people do not depend on radios and televisions as a source of information due to lack of power for operating these sources in the study area. This variable was significant and positively correlated $(\beta=0.114 ; \mathrm{p}<0.05)$. The model suggests an exchange of information through traditional ways increases the probability of use by $3.5 \%$ and intensity in decisions making on water resources conservation by $11.8 \%$ of the entire respondents. Onyango et al. (2014) observed high spread and use of traditional forecast through traditional means in absence of scientific forecast. In these areas, traditional forecast and previous experience remain the only basis for farm-level decisions pertaining to the coming season. The wealth status was significant and positively correlated $(\beta=0.072 ; p<0.05)$ with the use of weather and climate information for water resources conservation decisions. Even though the majority of the household had low income, the model suggests that they had the probability of use by $1.6 \%$ and increased intensity of decision to conserve water resources by $7 \%$ of the entire sample. This could be explained by other factors such as the size of land used for agriculture which 
when positively managed, it has a positive impact on conservation of water resources.

Farming was the main socio-economic activity in the area which was hypothesized to influence negatively water resources conservation $(ß-0.152 ; \mathrm{p}<0.05)$. If farmers are not educated enough they may opt to maximize farming output at the expense of water resources which they solely depend on especially during dry season. For a unit increase in farm costs, the probability of use of weather and climate information declined by $3.3 \%$ and intensity in water resources conservation affected by $1.47 \%$. The education level had significant and negative influence on the use of climate information in conserving water resources $(\beta=-0.111 ; p<0.05)$. For a unit decrease in education level, the use of weather and climate information declines by $2.5 \%$ and the intensity of decisions appropriate for water conservation are affected by $10.8 \%$. Farid et al. (2015) support this observation through a study in Northern Bangladesh which noted increase in education level has a significant effect on use of technology, that is, rate of use is higher with the increases of level of education and vice versa. About 85 percent of people in study villages are low adopters because they have a primary school education; hence the negative sign of coefficient implies that these farmers had lower probability and intensity in using weather and climate information to conserve water resources.

\section{Conclusion and Recommendations}

This study has found that the majority of respondents in Kilombero River catchment use weather and climate information in decisions on conservation of water resources with ten decisions identified in the area. The extent of use was medium and evenly distributed in the study area. Scientific climate attributes, extension visits, traditional methods, wealth status, economic activity and education level were the main factors identified to best explain the use of weather and climate information in decisions on conservation of water resources. Most of these decisions are, however implemented through legislation. The study recommends policy makers to emphasize these factors which best explain climate information use in the area. Future research is also essential in order to unravel the actual contribution of each approach to the overall use of weather and climate information in water resources conservation.

\section{References}

Ambani, M \& Abalabe, S. (2017), "Impact assessment on climate information services for community based adaptation to climate change", Niger Country Brief, CARE, 10.

Bergkamp, G., Orlando, B. \& Burton, I. (2003), "Adaptation of water resources management to climate change", International Union for Conservation of Nature, Gland, Switzerland and Cambridge, UK, 53.

Bergkamp, G., Orlando, B. and Burton, I., 2003. Adaptation of water resources management to climate change. International Union for Conservation of Nature (IUCN).

Bryan, E. Deressa, T.T. Gbetibouo, G.A. \& Ringler, C. (2009), "Adaptation to climate change in Ethiopia and South Africa", Options and constraints, Environmental science \& policy, 12(4), 413-426.

Bryan, E. Deressa, T.T. Gbetibouo, G.A. \& Ringler, C. (2009),"Adaptation to climate change in Ethiopia and South Africa", Options and constraints, Environmental science \& policy, 12(4), 413-426.

Farid, K.S., Tanny, N. Z. \& Sarma, P.K. (2015), "Factors affecting adoption of improved farm practices by the farmers of Northern Bangladesh" Journal of the Bangladesh Agricultural University, 13(2),291-298.

Gunasekera, D. (2010), "Use of climate information for socio-economic benefits", Procedia Environmental Sciences, 1,384-386.

Hansen, J., Baethgena, W., Osgooda, D., Ceccatoa, P. \& Ngugib, R. K. (2007), "Innovations in climate risk management", protecting and building rural livelihoods in a variable and changing climate, An Open Access Journal published by ICRISAT, Vol 4, 1-38.

Harrison, P. (2006), "Socio-Economic Baseline Survey of Villages Adjacent to the Vidunda Catchment Area", Bordering Udzungwa Mountains National Park, World Wide Fund for Nature Tanzania Programme Office, WWFTPO, 67.

Idrisa, Y. L., Ogunbameru, B. O., Ibrahim, A. A. \& Bawa, D. B. (2012), “Analysis of Awareness and Adaptation to Climate Change among Farmers in the Sahel Savannah Agro-ecological Zone of Borno State", Nigeria, British Journal of Environment and Climate Change, 2(2), 216 - 226.

Lyon, S. W., Koutsouris, A., Scheibler, F., Jarsjö, J., Mbanguka, R., Tumbo, M., Robert, K. K., Sharma, A. N. \& Velde, Y. (2015), "Interpreting characteristic drainage timescale variability across Kilombero Valley", Tanzania, Hydrological Processes, 29(8),1912 - 1924.

Maponya, P. \& Mpandeli, S. (2013), "The role of extension services in climate change adaptation in Limpopo province", South Africa, Journal of Agricultural Extension and Rural Development, 5(7):137-142.

Onyango, E., Ochieng, S. and Awiti, A.O. (2014), "Weather and climate information needs of small-scale farming and fishing communities in western Kenya for enhanced adaptive potential to climate change", In Proceedings of Sustainable Research and Innovation Conference, 187-193.

Sileshi, M., Nyikal, R. \& Wangia, S. (2012), "Factors affecting loan repayment performance of smallholder 
farmers in East Hararghe" Ethiopia, Developing Country Studies, 2(11), 205 - 213.

Van Aelst, K. \& Holvoet, N. (2018), "Climate change adaptation in the Morogoro Region of Tanzania", women's decision-making participation in small-scale farm households, Climate and Development, 10(6): 495-508.

Wilson, E. McInnes, R. Mbaga, D. P. \& Ouedaogo, P. (2017), "Ramsar Advisory Mission Report", Ramsar Advisory Mission Report, Gland, Switzerland, 78. 